\title{
Caracterização dos sistemas ambientais do Rio Grande do Norte: um enfoque na Depressão Sertaneja
}

\author{
Description of the environmental systems of Rio Grande do Norte: focus in a Backlands \\ Depression
}

\author{
Oliveira $^{1}$, A. V. L. C. de.; Cestaro ${ }^{2}$, L. A. \\ vilaneide_oliveira@yahoo.com.br
}

\begin{abstract}
Resumo
Este trabalho tem o objetivo de caracterizar a área da depressão sertaneja do Rio Grande do Norte, enquanto sistema ambiental do estado a partir da abordagem geossistêmica. Para tanto, foi realizada intensa revisão bibliográfica, além de trabalho de campo e elaboração de cartas temáticas acerca das caraterísticas físico/ambientais da Depressão Sertaneja do Rio Grande do Norte. Assim, foi possível observar que na área da Depressão Sertaneja os componentes dos sistemas interagem de maneira dinâmica, dando resultado às paisagens atuais, além de forte interação com os sistemas vizinhos, tornando diversas as paisagens na Depressão Sertaneja. Também foi possível perceber que as caracterisiticas naturais e os usos estão fortemente relacionadas às fragilidades na referida área de estudo.
\end{abstract}

Palavras-chave: Depressão Sertaneja; Semiárido; Geomorfologia.

\begin{abstract}
This work there is na objective of describe an Backlands Depression of Rio Grande do Norte like a environmental system using the geosystemic approach. Therefore, it was conducted a hard bibliographic review, fieldwork and were made thematics maps that contains fisics/environmental characterístics of the Backlands Depression of the State Rio Grande do Norte. Therefore, it was possible to observe that inside of the Backlands Depression the components interact dynamically, thats because the landscapes are rigth now and it interact with the neighbors system that forming the several Backlands Depression landscapes. So, was possible to perceive that the natural characteristics and the others uses there are strong relationships with the fragilities at the work's área.
\end{abstract}

Keywords: Backlands Depression; Semiarid; geomorphology.

\section{INTRODUÇÃO}

Compreendendo a paisagem como um conjunto inter-relacionado de formações naturais e antroponaturais (RODRIGUEZ; SILVA; CAVALCANTE, 2007), é possível entender que essa categoria abarca diversas características do meio e ainda suas inter-relações, sendo complexa a tarefa de definir ou classificar as várias unidades de paisagem de um local. Desse modo, o caminho percorrido para esse tipo de definição é utilizar uma ou duas características do meio para realização de uma primeira classificação.

Desse modo, uma das formas regionalizar e tipificar as várias unidades da paisagem é utilizar o relevo como variável de referência, pois resulta da combinação de diferentes componentes da natureza, e é um importante recurso para a delimitação das paisagens, ao mesmo tempo em que quase sempre condiciona a forma de uso e ocupação do solo (CASSETI, 2005).

$\mathrm{Na}$ compartimentação geomorfológica do Brasil convencionou-se utilizar termos geomorfológicos amplos, tais como, Planícies, Planaltos e Depressões, sendo este último o cerne da ${ }^{I}$ Antônia Vilaneide Lopes Costa de Oliveira, Programana de Pós-Graduação e Pesquisa em Geografia (doutorado),UFRN, Natal, RN, Brasil.

${ }^{2}$ Luiz Antonio Cestaro, Professor do Programana de Pós-Graduação e Pesquisa em Geografia ,UFRN, Natal, RN, Brasil. 
discussão deste trabalho. Assim, entre as maiores depressões geomorfológicas do Brasil é possível citar a Depressão Sertaneja, que será o foco do trabalho, mais precisamente a Depressão Sertaneja no estado do Rio Grande do Norte $(\mathrm{RN})$.

Dessa forma, este trabalho tem o objetivo de caracterizar a área da Depressão Sertaneja do Rio Grande do Norte, enquanto sistema ambiental do estado a partir da abordagem geossistêmica, compreendendo que é de fundamental importância conhecer as características naturais das áreas de atuação, principalmente nas etapas de planejamento, pois, qualquer interferência na natureza, pelo homem, necessita de um estudo que leve ao diagnóstico, ou seja, a um conhecimento de quadro ambiental onde se vai atuar (ROSS, 2005).

\section{METODOLOGIA}

No Rio Grande do Norte, as áreas de depressão e suas subdivisões em nível de maior detalhe foram abordadas observando a divisão em sistemas ambientais proposto por Cestaro et al. (2007), no qual houve o apoio para a delimitação das unidades deste trabalho.

Assim, foi realizada a caracterização climática, geológica, geomorfológica, pedológica e vegetacional da área de estudo.

Para tanto, foram utilizados os arquivos shapefile de limites municipais e da rede de drenagem, disponibilizados no sítio do IBGE (Instituto Brasileiro de Geografia e Estatística); mapa geológico da área em estudo segundo Angelim et al (2006); Mapa geológico segundo Gomes et al., (1981); mapa exploratório de solos segundo Souza et al., (1981); mapa geomorfológico segundo Prates; Gatto; Costa (1981); mapa de vegetação segundo Salgado; Jordy Filho; Gonçalves, 1981; Manual Técnico de Vegetação do IBGE para associação da nomenclatura atual, bem como, para identicação das características dos grupos vegetacionais da área; Imagens SRTM (Shuttlle Radar Topography Mission) obtidas no site do INPE (http://www.dsr.inpe.br/topodata/acesso.php) com resolução espacial de 30m, além de GPS (Sistema de Posicionamento Global) para utilizar em trabalho de campo, etapa necessária para a redefinição de contornos dos mapas e identificação de características, principalmente em áreas limítrofes, pois a utilização de mapas de grande escala em trabalhos de maoir detalhe requer a investigação das características que foram generalizadas.

Todos os dados supracitados foram interpretados e analisados conjuntamente, observando suas relações dentro do sistema estudado e com os sistemas vizinhos. Já o processamento dos dados espaciais foi realizado no software ArcGis 10.2. 


\section{RESULTADOS E DISCUSSÃO}

A área de estudo do presente trabalho está localizada no nordeste brasileiro, mais precisamente no estado do Rio Grande do Norte (FIG.1) e foi classificada como Região natural da Depressão Sertaneja, segundo Cestaro et al. (2007).

Enquanto região natural, a Depressão Sertaneja se divide em dois geossistemas, segundo o mesmo autor, a Depressão Sertaneja Semiárida Interiorana, localizada na porção central e oeste do estado, e a Depressão subúmida oriental, localizado na porção mais a leste do estado, na área conhecida como agreste potiguar, correspondendo a um total de aproximadamente 2.200.573,7182 hectares, se configurando o maior sistema ambiental, na categoria de Região natural, do Rio Grande do Norte.

Além do nível de geossistemas, a compartimentação da Depressão Sertaneja, segundo Cestaro, et al., (2007), chegou ao nível de geofácies, dividindo-se em quatro (4) geofácies, a saber: Depressão Subúmida plana e suavemente ondulada, Depressão subúmida com relevo movimentado, ambas pertencentes ao geossistema da Depressão subúmida oriental; e Depressão semiárida plana e suavemente ondulada, Depressão subúmida com relevo movimentado, pertencentes ao geossistema da Depressão semiárida interiorana. Cabe rasaltar que os limites cartográficos das geofácies ainda não foram definidos.

\subsection{CARACTERIZAÇÃO DA DEPRESSÃO SERTANEJA DO RIO GRANDE DO NORTE}

Os elementos caracterizados foram cobertura vegetal, clima, relevo, geologia, hidrografia, solos e a ocupação/exploração humana.

Para caracterização dos aspectos climáticos foram considerados os levantamentos do Projeto RADAMBRASIL (1981), segundo Azevedo e Moreira (1981). No referido trabalho, para definição de clima regional e suas variações mesoclimáticas foram consideradas os elementos de índices de umidade de Thornthwaite, precipitação total anual, excedente hídrico, deficiência hídrica anual e número de meses com excedente hídrico. Também foi utilizado o mapeamento dos tipos climáticos do Rio Grande do Norte, conforme Diniz e Pereira (2015), que divide o estado nos tipos climáticos Tropical do Nordeste Oriental e Tropical de Zona Equatorial, subdividos em subdomínios climáticos.

Assim, para área da Depressão Sertaneja foi identificado o subdomínio climático semiárido, com variedades climáticas branda, mediana e forte. Além disso, na área de transição entre o sistema da Depressão subúmida oriental e Tabuleiros costeiros, foi possível identificar o subdomínio 
climático subúmido, no entanto, por se tratar de área de transição e ser pouco presente na área de estudo, esse subdomínio climático não foi caracterizado.

O semiárido representa o subdomínio climático de maior representatividade espacial no Rio Grande do Norte. As precipitações variam de 500 a $800 \mathrm{~mm}$ com índices de umidade negativo e deficiência hídrica no solo de 500 a 1.200mm anuais, por um período de 6 a 10 meses e temperaturas médias anuais entre $24 \mathrm{C}^{\circ}$ e $27 \mathrm{C}^{\circ}$.

Para Azevedo e Moreira (1981), ainda é possível citar uma região climática de transição Semiárido a árido, apresentando-se com manchas a sotavento da Borborema, com precipitações entre 250 e 500mm anuais, sendo o índice de umidade negativo e elevada deficiência hídrica em um período de estiagem de 10 a 12 meses ao ano, sem excedente hídrico, características compatíveis com o semiárido forte, proposto pelos autores citados anteriormente.

Assim, mesmo tendo como proposta inicial a caracterização da área da Depressão Sertaneja do Rio Grande do Norte, no decorrer da pesquisa, foi possível perceber que seria necessário redefinir a nomenclatura do geossistema da Depressão subúmida oriental, pois não havia uma característica marcante de clima subúmido para referida área, mas sim de um semiárido brando a mediano. Nesse sentido, o geossistema da Depressão subúmida oriental será referenciado como geossistema da Depressão oriental de semiárido brando a mediano, sendo apresentado com os mesmo limites cartográficos.

Figura 1: Localização da Depressão Sertaneja no Estado do Rio Grande do Norte

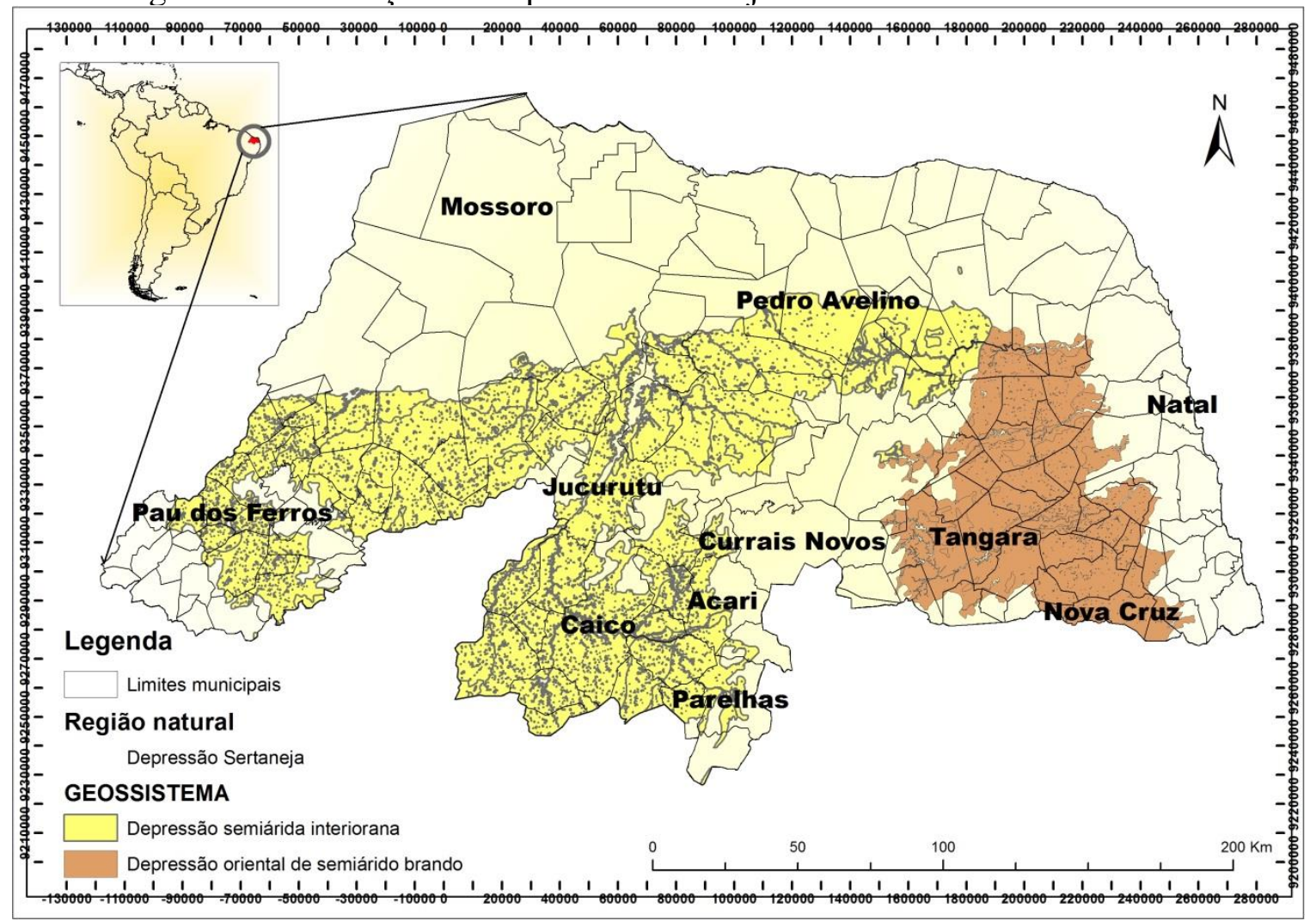


Com relação a caracterização geológica da área da Depressão Sertaneja, utilizou-se os dados do projeto RADAMBRASIL (1981) segundo Gomes et al., (1981), bem como, os dados da CPRM segundo Angelim et al. (2006).

A área da Depressão Sertaneja está inserida em terreno cristalino, composto por rochas ígneas e metamórficas. Utilizando uma escala cronológica que vai do pré-cambriano inferior ao superior é possível realizar uma caracterização das estruturas mais antigas do Complexo Caicó, passando pelas estruturas do pré-cambriano superior da Formação Seridó, Formação Jucurutu e pequenas áreas da Formação Equador, além de suítes magmáticas que se formaram de maneira intrusiva nas estruturas antes existentes. Esses corpos intrusivos foram denominados de suítes intrusivas, são elas: Suíte Poço da Cruz, Suíte Dona Inez, Suíte São Joao do Sabugi, Suíte Catingueira, Suíte Itaporanga, Suíte Serra do Deserto, Suíte Umarizal.

O Complexo Caicó é representado por gnaisses e migmatitos constituídos principalmente por quartzo, feldspato e minerais micáceos, além de minerais acessórios como a muscovita.

Na Formação Jucurutu os representantes litológicos são, biotitas gnaisse, gnaisse-quartzofeldspático, incluindo intercalações de xistos, quartzitos, calcário metamórfico (mármore), calcossilicáticas contendo scheelita e formações ferríferas. Já a Formação Seridó está representada litologicamente por biotita xistos, muscovita-biotita xisto com granada, filitos com intercalações de gnaisses, anfibolitos, calcário cristalino e quartizito. A Formação Equador por ser pouco presente na área de estudo não foi caracterizada.

Quanto aos solos foram utilizados dados do Projeto RADAMBRASIL (1981), segundo Souza et al., (1981) e os levantamentos da EMBRAPA segundo Santos et al., (2013), pois foi necessário adaptar as nomenclaturas dos levantamentos de Souza et al., (1981) ao novo Sistema Brasileiro de Classificação de Solos (2013) proposto pela EMBRAPA. Assim, foram identificados para área de estudo os seguintes tipos de solos:

\begin{tabular}{|l|l|l|}
\hline Tipo de solo & \multicolumn{1}{|c|}{ Localização } & \multicolumn{1}{c|}{ Principais características } \\
\hline Planossolos & $\begin{array}{l}\text { Depressão oriental de semiárido brando a } \\
\text { mediano. } \\
\text { Também na região do sertão de Angicos, } \\
\begin{array}{l}\text { Pedro Avelino, Triunfo Potiguar, na área da } \\
\text { Depressão semiárida interiorana. }\end{array}\end{array}$ & $\begin{array}{l}\text { Solos rasos a pouco profundos com elevadas concentrações de } \\
\text { sódio e pH ácido. Apresentam horizonte B textural, argiloso e } \\
\text { semipermeável, resultando em solos hidromórficos de } \\
\text { drenagem deficiente. Na região do Sertão de Angicos, Pedro } \\
\text { Velho e Triunfo Potiguar esses solos se apresentam com alta } \\
\text { salinidade, pedregosos, pouco profundos, imperfeitamente } \\
\text { drenados e originados de rochas cristalinas. }\end{array}$ \\
\hline Neossolos & $\begin{array}{l}\text { Sertão potiguar correspondente a área do } \\
\text { sistema da Depressão semiárida interiorana } \\
\text { associados a afloramentos de rochas e em uma } \\
\text { pequena da Depressão oriental de semiárido } \\
\text { brando a mediano. }\end{array}$ & $\begin{array}{l}\text { Solos pouco desenvolvidos, rasos e com comum } \\
\text { minerais primários. } \\
\text { Por vezes, com cascalho e baixos teores de matéria orgânica. }\end{array}$ \\
\hline Nitossolos & Distribuído por toda área da Depressão & Solos medianamente profundos, fortemente a moderadamente \\
\hline
\end{tabular}




\begin{tabular}{|l|l|l|}
\hline & Sertaneja. & drenado, geralmente ácidos, mas de boa fertilidade. \\
\hline Luvissolos & $\begin{array}{l}\text { Solos típicos do sertão potiguar, com maior } \\
\text { ocorrência na região do Seridó. }\end{array}$ & $\begin{array}{l}\text { Solos rasos a pouco profundos com pedregosidade e } \\
\text { afloramento rochoso com consistência muito dura quando seco } \\
\text { e pegajosa quando úmido. }\end{array}$ \\
\hline Latossolos & $\begin{array}{l}\text { Em uma pequena porção na região do agreste } \\
\text { potiguar correspondente a área do sistema da } \\
\text { Depressão oriental de semiárido brando a } \\
\text { mediano. }\end{array}$ & $\begin{array}{l}\text { Solos medianamente profundos a profundos, fortemente a } \\
\text { moderadamente drenados, com baixos teores de matéria } \\
\text { orgânica. }\end{array}$ \\
\hline
\end{tabular}

Quadro 1: Solos identificados na Depressão Sertaneja. Fonte: Souza et al., (1981); Nunes (2006); Santos et al., (2013).

Quanto aos aspectos do relevo, a caracterização se apoiou nos resultados de Prates; Gatto; Costa (1981) e do Modelo Digital do Terreno (MDT) gerado a partir de imagens SRTM. Conforme a Prates; Gatto; Costa (1981), a área em estudo está totalmente inserida na Unidade Geomorfológica da Depressão Sertaneja, marcada por superfície pediplanada elaboradas por processos de pediplanação em diversos tipos litológicos.

Ainda segundo os referidos autores, as formas de dissecação na Depressão Sertaneja são Formas aguçadas de relevo de topo contínuo e aguçado, com diferentes ordens de grandeza e de aprofundamento de drenagem, separados geralmente por vales em V; Formas convexas com relevo de topo convexo com diferentes ordens de grandeza e de aprofundamento de drenagem separados por vales em V e eventualmente por vales de fundo plano; e Formas tabulares - relevo de topo plano, com diferentes ordens de grandeza e de aprofundamento de drenagem separados geralmente por vales de fundo plano.

De acordo com Ab’Sáber (1969), a Depressão Sertaneja é formada por pediplanos modernos localizados no entorno da Borborema, criando condições excepcionais para compartimentação topográfica dessa região, como é possível observar na imagem abaixo.

Quanto aos aspectos da hidrografia da área da Depressão Sertaneja é possível perceber que os rios localizados no sistema da Depressão Semiárida interiorana escoam no sentido Sul-Norte, são rios intermitentes ou perenizados pela construção de barragens. Assim, têm-se nessas áreas da Depressão Sertaneja duas bacias hidrográficas principais, a Bacia do Rio Apodi-Mossoró, segunda maior do estado, e a Bacia do Rio Piranhas-Açu, a maior do estado. Na primeira o principal reservatório e a Barragem de Santa Cruz no município de Apodi, já na segunda é a Barragem Engenheiro Armando Ribeiro Gonçalves entre os municípios de São Rafael, Assu, Itaja e Jucurutu, sendo o maior do estado, ocupando uma superfície de $17,500 \mathrm{~km} 2$, correspondendo a 32,8\% do território estadual (NUNES, 2006).

No sistema da Depressão oriental de semiárido brando a mediano os rios escoam no sentido Oeste-Leste e as principais bacias hidrográficas são, a bacia do Rio Potengi, a Bacia do Rio CearáMirim, Bacia do Rio Trairí, Bacia do Rio Jacu e Bacia do Rio Curimataú. 
Para caracterização dos aspectos da cobertura vegetal da Depressão Sertaneja foi utilizado o mapa e a descrição da vegetação do projeto RADAMBRASIL (1981), que utilizou para tal descrição o conceito de regiões fitoecológicas, considerada uma "região ecológica como uma área de florística bem determinada, de formas biológicas características, que se repetem dentro de um mesmo clima, podendo ocorrer em terrenos de litologia variada" (SALGADO; JORDY FILHO; GONÇALVES, 1981).

De acordo com sistema classificação em regiões fitoecológicas supracitada foi identificada uma região fitoecológica para área em estudo, a Estepe (Caatinga), além de das áreas Antrópicas e de Tensão Ecológica do tipo ecótono. Em classificações mais recentes do IBGE (2012), a Estepe (Caatinga) foi chamada de Savana-Estépica, para denominar tipologias vegetais campestres, em geral, com estrato lenhoso decidual e espinhoso, distribuídas em diferentes quadrantes do Território Nacional. A Savana-Estépica (Caatinga) compreende as formações xerófitas lenhosas deciduais, em geral espinhosas, de folhas pequenas, além de plantas suculentas e tapete herbáceo estacional (SALGADO; JORDY FILHO; GONÇALVES, 1981). Essa região fitoecológica de divide em dois tipos fisionômicos, a saber: a Estepe Arbórea Densa e a Estepe Arbórea Aberta, sendo o segundo de maior ocorrência para área estudada.

A Estepe Arbórea Aberta é uma formação das áreas pediplanadas, compostas de árvores e arvoretas de alturas variáveis, esparsamente distribuídas revestindo uma grande parte da Depressão Sertaneja, caracteriza-se por duas fisionomias, uma em fase de regeneração, típica de áreas que sofreram cortes, com um grupo florístico denominados de espécies pioneiras, como por exemplo, a jurema-preta (Mimosa hostilis). Já a Estepe Arbórea Densa é uma formação arbórea baixa, localizada nas áreas residuais do pediplano nordestino e de inselbergs, sendo de ocorrência limitada.

Na classificação das áreas de Tensão Ecológica tem-se o contato Estepe/Floresta Estacional, principalmente no extremo leste da Depressão oriental de semiárido brando a mediano. São áreas onde ocorre a transição climática e geológica, onde se constata uma mistura de espécies e que levam esse nome devido a competição de espécies de diferentes tipos de vegetação. Na Depressão Sertaneja, o contato, definido como ecótono, encontra-se próximo aos Tabuleiros Costeiros, cobertos pela Floresta Estacional.

\subsection{INTERAÇÕES E PROCESSOS NA DEPRESSÃO SERTANEJA}

A partir da Teoria Geral dos Sistemas proposta por Bertallanffy, novas concepções passaram a ser formuladas em todas as ciências, e não foi diferente quanto aos estudos do relevo. As noções de sistemas abertos (importação e exportação de massa e energia) e de equilíbrio (um ajustamento 
contínuo entre o comportamento dos processos e as formas resultantes) visto em diferentes escalas, passaram a fazer parte de uma nova teoria, o equilíbrio dinâmico. Nessa perspectiva, as formas de relevo, por exemplo, serão resultado contínuo de um ajuste entre o comportamento dos processos e o nível de resistência do material que está sendo trabalhado, também deixam de ser algo estático para serem também dinâmicas (MARQUES, 1998).

Assim, na área da Depressão Sertaneja os componentes dos sistemas interagem de maneira dinâmica, dando resultado às paisagens atuais. Nesse sentido, entre as áreas elevadas do Planalto da Borborema, que é um importante dispersor da drenagem, formam-se zonas aplainadas onde os processos denudacionais suplantaram os agradacionais, formando as vastas superfícies erosivas da Depressão Sertaneja (AB’SABER, 1969), que, por possuir características erosivas apresentam solos pouco profundos e pedregosos.

Segundo Salgado; Jordy Filho; Gonçalves (1981), por apresentar uma área relativamente extensa, com uma certa variedade de formas de relevo, ocorre uma variedade de tipos de vegetação. Outrossim, onde o índice de aridez é maior e ocorre a presença de Solos litólicos, torna-se notório o desaparecimento de algumas espécies, restando aquelas consideradas altamente especializadas para essas condições ecológicas, aumentando o número de cactáceas e ao mesmo tempo as espécies arbóreas apresentam maior espaçamento entre si e altura reduzida.

Nos dois geossistemas da Depressão Sertaneja os solos também são reflexos dos tipos de clima, sendo mais desenvolvidos na área da Depressão oriental de semiárido brando a mediano onde ocorre a atuação quase igual do intemperismo físico e químico, devido a umidade da área, e solos pouco desenvolvidos na área da Depressão semiárida interiorana, onde o intemperismo físico tem maior atuação, além de serem mais duros devido o período de estiagem, resultando em processos erosivos mais intensos devido a consistência dura, o relevo ondulado, a pouca espessura do solo, ao clima semiárido e a irrigação mal projetada. Além disso, os solos da área de estudo, são, na maioria, originário de rochas ígneas e metamórficas, fato que, associado às características supracitadas, os tornam suscetível a salinização.

A relação dos elementos de clima, rocha e relevo também é importante para que se compreendam as características atuais da área em estudo. Assim, devido a baixa umidade, a área de estudo apresenta uma considerável amplitude térmica, tendo dias mais quentes e noite mais frias, isso causa dilatação dos minerais da rocha durante o dia e contração a noite, causando desagregação mecânica da rocha, fenômeno que influencia fortemente o recuo paralelo das vertentes no processo de pediplanação (CASSETI, 2005).

O clima também tem fortes relações com a hidrografia da área, pois, por ter baixas precipitações e altas taxas de evaporação, os rios são intermitentes na área da Depressão Sertaneja. 
O sistema analisado também possui relação com os planaltos residuais e as planícies fluviais. Os relevos residuais são fornecedores de sedimentos para o processo de pediplanação, pois são eles que sofrem recuo paralelo, através da erosão, oferecendo sedimento para o mascaramento das irregularidades topográficas, caracterizando a morfologia dos pediplanos (CASSETTI, 2005).

No que concerne à relação da Depressão Sertaneja com as planícies fluviais é possível perceber que as planícies fluviais em áreas da Depressão Sertaneja, mesmo sendo formada por rios intermitentes, funcionam como transportadores de sedimentos, principalmente nos períodos de chuvas.

As características físicas da Depressão Sertaneja oferecem a essa região uma fragilidade ambiental relacionada a processos erosivos e salinização dos solos. Além disso, as formas de uso da terra também podem intensificar a perda da capacidade produtiva do solo (desertificação).

Os processos erosivos estão associados ao relevo ondulado e, principalmente, aos solos rasos de consistência e coesão dura e baixa capacidade de infiltração, resultando em um escoamento mais superficial que leva o solo em períodos chuvosos concentrados em poucos meses. Os solos originários de rochas cristalinas apresentando elevada concentração de sais, como o sódio nos solos Planossolo solódico, aumentado também a suscetibilidade a salinização. Já os usos dos solos relacionados a agricultura de irrigação mal projetada, a pecuária extensiva e retirada intensa da vegetação de caatinga, também aumentam a fragilidade ambiental da área frente aos processos de perda da capacidade produtiva do solo e perda de vegetação, resultando em áreas relacionadas ao processo de desertificação.

Desse modo, é possível entender que os elementos do meio interagem para formar e diferenciar os sistemas ambientais, e que os estudos e a compreensão desses sistemas se revelem objeto de estudo da ciência geográfica, pois temos a paisagem como um conceito geográfico que emerge quando se busca compreender sistemas ambientais como a Depressão Sertaneja.

\section{CONSIDERAÇÕES FINAIS}

Ao término deste trabalho é possível afirmar que muito se avançou sobre os estudos da Depressão Sertaneja, principalmente com as colaborações de geográfos como Ab’Sáber e Ross, no que se refere a estudos próprios para o Brasil. No entanto, pensando em abordagem integradora própria para a Depressão Sertaneja, os estudos referentes às fragilidades ambientais precisam avançar ainda mais, pois os trabalhos encontrados sobre a referida área ainda estão pautados em modelos de fragilidade que levam em consideração principalmente os aspectos de declividade, mas é possível perceber que as fragilidades da área de estudo também estão relacionadas a 
características naturais dos solos e do clima, elementos que precisam ser estudados concomitantemente aos de relevo e outros para que se estabeleçam as fragilidades de ambiente semiárido. Também foi possível conhecer o quanto são diversas as paisagens da Depressão Sertaneja do Rio Grande do Norte, e como o processo de apropriação e uso está relacionado aos impactos ambientais na maior região natural do estado.

\section{REFERÊNCIAS}

ANGELIM, L.A.A., Medeiros, V.C., Nesi, J.R. 2006. Programa Geologia do Brasil -PGB. Projeto Geologia e Recursos Minerais do Estado do Rio Grande do Norte. Mapa geológico do Estado do Rio Grande do Norte. Escala. 1:500.000. Recife: CPRM/FAPERN, 2006.

AB' SABER, Aziz Nacib. Participação das superfícies aplaindas nas paisagens do Nordeste brasileiro. Geomorfologia, São Paulo, n. 19, p. 1-38, 1969.

AZEVEDO, Lorisa Maria Pinto; MOREIRA, Rita de Cassia. Climatologia. In: Brasil. Ministério das Minas e Energias. Secretaria-Geral. Projeto RADAMBRASIL. Folha SB. 24/25 Jaguaribe/Natal. Rio de Janeiro 1981.

CASSETI, Valter. $\quad$ Geomorfologia. $\quad$ [S.1.]: $\quad$ [2005]. Disponível em: <http://www.funape.org.br/geomorfologia/>. Acesso em 14 de abril de 2016.

CESTARO, Luiz Antonio, et al. Proposta de um sistema de unidades geoambientais para o Rio Grande do Norte. Universidade Federal do Rio Grande do Norte (UFRN), Fundação de Apoio a Pesquisa do Rio Grande do Norte (FAPERN), Instituto de Defesa do Meio Ambiente do RN (IDEMA), 2007.

DINIZ, Marco Túlio Mendonça; PEREIRA, Vítor Hugo Campelo. Climatologia do estado do Rio Grande do Norte, Brasil: sistemas atmosféricos atuantes e mapeamento de tipos de clima. Boletim Goiano de Geografia. Goiânia, v. 35, n. 3, p. 488-506, 2015.

GOMES, José Roberto de Carvalho, et al. Geologia. In: Brasil. Ministério das Minas e Energias. Secretaria-Geral. Projeto RADAMBRASIL. Folha SB. 24/25 Jaguaribe/Natal. Rio de Janeiro 1981.

IBGE. Instituto Brasileiro de Geografia e Estatística. Manual Técnico da Vegetação Brasileira: Sistema fitogeográfico, Inventário das formações florestais e campestres, Técnicas e manejo de coleções botânicas, Procedimentos para mapeamentos. Ministério do Planejamento, Orçamento e Gestão, Instituto Brasileiro de Geografia e Estatística - IBGE; Rio de Janeiro, 2012.

MARQUES, Jorge Soares. Ciência geomorfológica. In: GUERRA, Antonio Jose Teixeira; CUNHA, Sandra Baptista (Orgs.). Geomorfologia: uma atualização de bases e conceitos. 3. ed. Rio de Janeiro: Bertrand Brasil, 1998.

PRATES, Margarete; GATTO, Luiz Carlos Soares; COSTA, Maria Iranice Passos. Geomorfologia. In: Brasil. Ministério das Minas e Energias. Secretaria-Geral. Projeto RADAMBRASIL. Folha SB. 24/25 Jaguaribe/Natal. Rio de Janeiro 1981. 
RODRIGUEZ, José Manuel Mateo; SILVA, Edson Vicente da; CAVALCANTI, Agostinho Paula Brito. Geoecologia das paisagens: uma visão geossistêmica da análise ambiental. 2. ed. Fortaleza: Editora UFC, 2007.

ROSS, Jurandyr Luciano Sanches. Geomorfologia: ambiente e planejamento. 8. ed. São Paulo: Contexto, 2005.

SALGADO, Odilon Albino, et al. Vegetação: As regiões fitogeográficas, sua natureza e seus recursos econômicos - Estudo fitogeográfico. In: Brasil. Ministério das Minas e Energias. Secretaria-Geral. Projeto RADAMBRASIL. Folha SB. 24/25 Jaguaribe/Natal. Rio de Janeiro 1981.

SANTOS, Humberto Gonçalves et al. Sistema Brasileiro de Classificação de Solos. 3. ed. Rev. Amp.- Brasília - DF: EMBRAPA, 2013.

SOUZA, Celso Gutemberg, et al. Pedologia: Levantamento exploratório de solos. In: Brasil. Ministério das Minas e Energias. Secretaria-Geral. Projeto RADAMBRASIL. Folha SB. 24/25 Jaguaribe/Natal. Rio de Janeiro 1981.

Recebido em: 14/08/2016

Aceito para publicação em: 01/10/2016 